\title{
Deep Probing into Aesthetic Characteristics of Public Art's Development
}

\author{
Junmei Wang \\ Public Art Education Center, Xijing University, Xi'an, Shaanxi, 710123, China
}

\author{
Keywords: Public art, Development, Aesthetic characteristics
}

\begin{abstract}
Presently, public art has become one of the carriers of cultural communication. In modern times, when science and technology rapidly develop, the aesthetic sensory effect of public art is remarkably improved via the application of high technology and new materials, and the organic integration of visual sense and environmental space greatly increases the visual impact of public art. At the time of rapid development, public art also faces new challenges. It requires artists to be versatile in ways of artistic presentation and creating style, and capable of showing aesthetic consciousness and mastering the overall aesthetic appreciation in artistic creations.
\end{abstract}

\section{Introduction}

Public art can enrich people's spiritual life, beautify city environment, and add beautify sceneries to city. Besides, public art creation can shorten the distance between people and art, making people, surroundings, and art organically combine together, people taste the beauty of art in their surroundings, and people enjoy the beauty of environment while artistic appreciation. The technology and culture in modern times provide more materials, technology and ideas for public art creation. Contemporary arts also should make full use of the advantages of artistic creation in modern times to present beauty in a more special way and form.

\section{Contemporary Development of Public Art}

\section{Application of New Materials and New Technologies in Public Art}

Contemporary public art is expected to have a vast potential for future development. In contemporary public art, self-experience and rational cognition are emphasized, color, line and light are combined with modern symbols in artistic creation process, and the using of materials is especially surprising, bold and innovative. For example, wood materials, plastic materials, ferrous materials, glass materials, and stainless steel materials are adopted. The bountiful selection of materials greatly diversifies of forms of public art presentation and enriches artistic expression space.

Artistic creation can make people's surroundings more interesting and artistic, functional, and of high ornamental value and guidance value, raising people's life quality and enriching people's spirits by beautifying their surroundings. Contemporary public art should advance with the times by constant artistic innovations to follow the constantly progressing scientific, technological, cultural and aesthetic consciousness, and embrace new technologies and ideas in modern times, so as to achieve artistic and aesthetic resonance by combining traditional art with contemporary elements, and create public art of modern visual beauty. With the development of transport, light railway, metro and other indoor means of transportation are widely used in cities. For purpose of letting people at ease during travel, and enriching their visual aesthetic ideas, lots of frescoes appear in metro and light railway stations. Various materials are adopted to paint such frescoes, and the decorative styles are also not limited, typically representing modern art. The main presentation forms include polished lacquer painting, stone carving, crystal imbedding, and mixed materials. Thus, railways are embraced 
by modern public spatial art atmosphere. These artistic creations are made in such a way to coordinate with the modern transportation system, and express the new style and features of cities in new era to people. It is thus clear that by integrating new technology and new materials with art, more diversified presentation forms and more prominent aesthetic effect can be achieved, and a vaster space for artistic creation is created.

\section{Aesthetic Interaction among Appreciators, Surroundings, and Artistic Works}

The aim of public art creation is to guide people to find their ideal space in their living environment, to get inner sustenance via experience in such space. Aesthetic action is inextricably linked with social harmony, for aesthetic action itself aims to reach a harmony. Public art has experienced a long history since its emergence, and has constantly evolved. Despite that the presentation form, materials and creative ideas always keep changing and reforming, public art has been essentially aiming to provide desired life experience to society and people.

Public art is to serve the public. Hence, public art is humanistic different from other types of art. Such a feature of public art does not only draw art near to daily life of people, but also gives different moods to people at different levels and with different experiences, so as to make people percept art and understand life more thoroughly and really. Modern public art subtly integrates people's emotions with material needs, emphasizes appreciators' ideas and humanistic consciousness, and takes the interactivity between art and surroundings as the main creative idea. Surroundings will affect appreciators' aesthetic taste to a certain extent, and appreciators' aesthetic feelings also will be shown via artistic appreciation in turn. For example, an appreciator in a narrow space will feel constrained, and will bring his emotion in artistic works to be appreciated. In such a case, even if the works shows magnificence and vastness, the appreciator will not feel it.

According to the analyses above, the interaction between surroundings and appreciators is of great significance to artistic appreciation. Only the coordination among appreciators, surroundings and arts is taken into account in the creation of public art, can it be realized to bring emotions in art, combine people with art, and then sublimate emotions. Through the interaction among the three elements, the concept of public art radiates, fully plays its proper artistic value, and finally beautifies space environment and reflects the visual sense of beauty of appreciators.

\section{Combination of Functionality and Aesthetic Character of Art}

Beauty itself is a subjective consciousness of people, which can be felt only by combining people's observations, imaginations and emotions. What public art reflects is the progress of spiritual civilization of cities, the hub promoting people to communicate with life, and the representation of city enchantment. Integrating public art with other disciplines can both beautify people's living space, and meet people's spiritual needs and aesthetic needs, so as to achieve a direct resonance between public art and people's emotions, creating more livable and comfortable space for people, and making beauty resources be shared to an extreme.

Therefore, an overall investigation of environment, buildings and space should be made first before public art creations. Besides, the aesthetic perception of art and decorative function should be constructively combined, to present an all-around artistic result showing both aesthetic perception and decorative function. Such all-around art can greatly boost the economic and cultural development, and make the functions of public art of beautifying and aesthetical education play an efficient role.

\section{Required Art Cultivation for Public Artists}

\section{Multi-cultural Vision and Accomplishment}

Basically, traditional public art works are created based on history, myths, folk customs, and cultural tradition to analyze or illustrate such themes, which are inextricably linked with traditional culture and the mainstream color of society. Yet the materials for contemporary public art works are mainly drawn from humanities, social sciences, social phenomena, and natural environment, of which the 
range is wider than that of traditional public art works. Art works are embodiment of the experience, personalities, habits, views and values of creators. Hence, only creators with noble artistic appreciation capacity and keen social awareness can produce extraordinary meaningful works that surely will truly reflect people's living and social phenomena, guide people's life and artistic appreciation, and lead public art to a broader space where traditions are adhered to and advancement with the times is also made.

Take the example of frescoes in Jianghan Road Metro Station (Wuhan). The frescoes are presented in the form of embossment, of which the style and contents fully reflect the art vision and art cultivation level of the creator. Jianghan Road is a major commercial area in Wuhan, which is taken as the hitting-point of the frescoes. Besides, a great deal of modern elements about the history of commercial development are included. In order to present lifelike pictures, artist specially selected historically representative visual elements and original life landscapes to effectively integrate history with reality, aesthetic appreciation with life, tradition with modern era in the works, to produce beautiful works[3]. The representation of public art provides richer life styles to people by fully integrating human, surroundings and art together into urban culture development.

\section{Rich and Bold Artistic Originality}

In modern public art works, both materials and techniques become increasingly diversified. Artists comprehensively utilize the techniques of stone carving, polished lacquer painting, and pigment painting to present different art forms of abundant contents. This lays a foundation for the development of public art, and also artistically and aesthetically improve people's surroundings. Therefore, public artists are required to have the courage to try new techniques, and use new materials to completely show the artistic connotations and beauty of their works. Specifically, typical modern painting techniques include 3D printing technology and painting technique via gunpowder explosion. Take the example of the Riverside Scene at Qingming Festival displayed in China Pavilion at Shanghai World Expo. It is presented in a dynamic way via modern technology. The adopted technology helps people to form a strong visual impact. Besides, taking full advantage of modern materials also brings new development to public art. For example, the Show the Civilization (American) is presented to show the history and culture of human development in an audio-video way. This presentation form is adopted for the first time, and is also a typical representative of perfect integration of technology and art.

In the new historical period, science, technology and civilization rapidly develop, providing rich techniques, elements and materials for public art creation, and enabling artists to integrate and coordinate texture, tone, and material of works based on their needs to perfectly show their works at final.

\section{Diversified Creation Styles}

Modern public art has a broad space for development in respect of creating style. As said by $\mathrm{Mr}$. Li Zehou, beauty is a product of human society, and is of practical significance only to human and human society. As far as artists are concerned, they must take a tolerant attitude, and then they can integrate their creations with social reality and art trends, so as to have a new understanding of art, and show the style, features and aesthetic perspective of new era in their works.

The creation of public art works must be carefully and well designed, and incorporate abstract, image and concrete expression style. Besides realistic style and decorative style, artistic works also should properly incorporate various traditional and modern styles. Thus, the aesthetic appeal of works including idealism, romanticism, and expressionism can be fully presented by rich elements, models and modern designs.

\section{Considerations for Public Artists in Artistic Creation}

Previous Preparations for Public Art 
Public art works are not just commodities, but are an art form presented with a purpose to preventing wasting of resources. A clear understanding of the planning and essence of public art creation must be got first, so that a way to participate in public art creation can be clearly figured out. An excellent works requires that artist, before creation, make a proper design scheme[4] based on the environment, surrounding buildings and landscapes of the location where the works is to be presented, coordinate the works to be produced with the cultural environment and natural environment, make full use of advantages of public art creation, make multiple designs on multiple themes, and finally select an optimal design therefrom.

\section{Abandoning Common Customs and Ideas}

Creators will be subject to criticisms during their creation from art society, art organizations, other peers and the public, etc. As a result, some creators are liable to be constrained and interrupted by these factors when they want to adopt any new techniques, new materials or new ideas, and find it difficult to develop a bold design idea. Such negative and helpless feelings will be reflected in their works, and then hinder an emotional resonance between the works and spectators from being developed and people's aesthetic appreciation. Furthermore, it is hard for an artist greatly constrained to throw himself into his creation. Therefore, artists must be capable of abandoning ordinary criteria and boldly creating works based on artistic considerations.

\section{Developing Spirits of Solidarity and Collaboration to Expand the Path of Public Art Creation}

Every public artist have their unique creative ideas, thoughts and techniques and styles of expression. Integrating the ideas of artists into one will produce an amazing works. Though there are many divisions in art field, undeniably all these divisions have the same artistic pursuit, so they also are compatible with each other. Artists should recognize this, and learn from, refer to and coordinate with each other, to present new artistic ideas and works and broaden the path of public art creation.

\section{Conclusions}

To sum up, public art involves in multiple disciplines and fields, and the creation inspiration and ideas come from the aesthetic appreciation of architecture, reproduction of history, and utilization of various subject elements. The works of public art can shorten the distance between people and art, and coordinate and integrate people, social environment and art works. Particularly, there are more and more elements, materials and technologies that can be used for public art in modern times, enriching the creating techniques and ideas. Artists ought to dare to try new things, and make bold innovations, to present the beauty of art in diversified ways.

\section{References}

[1] Ye Zhiqiang. Coordination and Synchronization between Public Art and Urban Design, Hundred Schools in Arts, 2012(6): 239-240.

[2] Ding Xiao. Aesthetic Characteristics of Contemporary Development of Public Art, Journal of Wuhan University of Technology (Social Science Edition), 2014(3): 503-506.

[3] Li Jiansheng. Beijing Public Art and Urban Culture Construction of the Capital, Journal of Beijing Union University Humanities and Social Sciences, 2014, 12(2): 12-18.

[4] Wang Baohua, Yang Haozhong, Zhang Bin, et al. Primary Discussion of Aesthetic Value of Urban Public Art, Journal of Northwest University (Philosophy and Social Science Edition), 2011, 41(5): 170-171. 